\title{
Grade 3 learners' imagined identities as readers revealed through their drawings
}

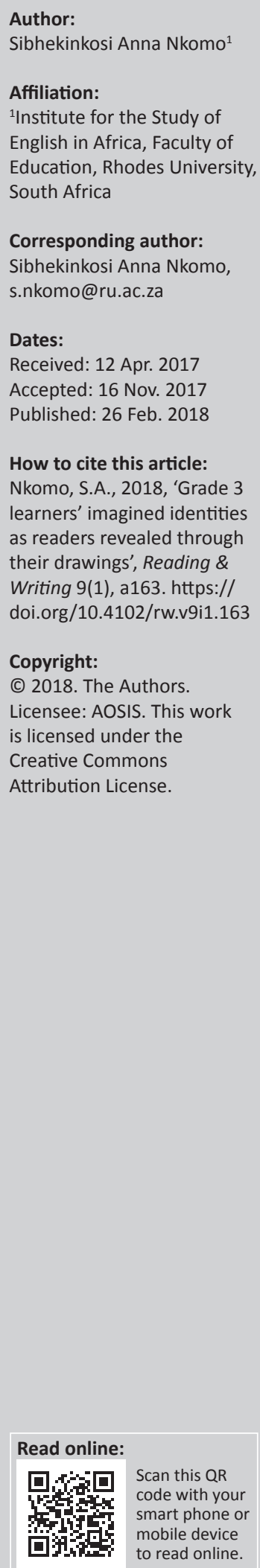

There has been limited attention towards the affective aspect in literacy development; yet, reading attitude, an affective component, is a significant element within literacy instruction. This makes a compelling case for investigating Grade 3 learners' attitudes towards reading. In this study, a situational analysis was conducted as Phase 1 of the research process before implementing a responsive reading programme at a primary school in Grahamstown, South Africa. In an effort to explore Grade 3 learners' attitudes, experiences and perspectives about reading, the study adopted the use of drawings, which is a child-centred approach. Learners were required to draw their perspectives or experiences about reading. In analysing the drawings, a range of semiotic theorists were integrated. Findings of the study indicate that by using drawings as a methodological tool, learners were able to provide detailed insights about their daily experiences with reading, attitudes towards reading and their varied individual views about reading. Such information gathered was vital for future consideration when implementing a responsive and extensive reading programme.

\section{Introduction}

Much focus has been placed on areas of measurable reading achievement, such as fluency, vocabulary and comprehension. This has resulted in reduced attention towards the affective component in relation to literacy development; yet, attitude as an affective component is a significant element within literacy instruction owing to its relationship with reading success. This article presents a subset of the results collected during Phase 1 of a larger study that was undertaken for my doctoral thesis. The main objective of the study was to investigate the nature of Grade 3 learners' attitudes towards reading.

The main study consisted of three different phases. Phase 1 of the study was the situational analysis or pre-intervention phase, which was then followed by Phase 2, the actual implementation phase of the extensive reading programme (ERP) and finally Phase 3, which was the evaluation of the ERP. In Phase 1 of the study, drawings were used alongside other data collection instruments such as focus group discussions. The drawings and the focus group discussions were used as methods of gathering learners' current attitudes and perceptions about reading. According to Freire (1984), education should be about acknowledging the knowledge that learners bring to the classroom. Therefore, this study acknowledges that in the classroom, each learner is unique and possesses knowledge that is unique based on the individual's historical, sociocultural and linguistic context. Hence, in this study, before implementing a reading programme, there was a need to understand and get a glimpse of the participants' attitudes and perceptions about reading. The learners' drawings about reading helped to uncover the reading narratives that learners bring to school and those that they acquire at school that might influence them to approach or avoid the reading activity.

The results of Phase 1 of the research reported on in this article show how learners effectively used drawings to represent their experiences and attitudes towards reading. The analysis of these drawings guided by a range of semiotic theories further indicates that learners have varied perceptions and experiences about reading, which might cause them to approach or avoid reading. Findings of this study have important implications for nurturing reading in the foundation phase (FP), which should be taken into account by teachers and other stakeholders interested in literacy development, so as to effectively cater for diverse learners and improve literacy levels. In addition, the information gathered through the drawings was used to help in designing and implementing a responsive reading programme.

\section{The importance of attitude in reading}

This study on learners' attitude towards reading stems from a concern that much emphasis placed on reading proficiency and other reading skills has often led teachers to ignore the importance of 
children's attitudes in the process of becoming literate. Yet, Cosgrove (2003) argues that instilling positive attitudes towards reading is just as fundamental as teaching decoding skills and comprehension strategies, as a positive attitude is essential for mastery of the printed page.

Sainsbury and Schagen (2004) argue that the emotional response to reading is the primary reason most non-readers do not read. There is also a perceived decline in interest for reading after the early years of schooling. It is therefore important for educators to implement early interventions in an effort to curb the attitudinal decline of learners (McKenna, Ellsworth \& Kear 1995). This study is important at a time when nationwide literacy results indicate that most of the South African learners cannot read (Spaull 2013). Research projects such as Progress in International Reading Literacy Study (PIRLS) (2006, 2011) and the National Education Evaluation and Development Unit (NEEDU) (2013), focusing on testing reading levels in South Africa, show that learners in this country perform significantly below the expected assessment standards. In order for learners to develop into successful readers, they must possess both the skill and the will to read. As noted by Guthrie and Wigfield (2000), motivation is what activates behaviour; hence, learners need to be motivated to read in school for academic purposes and they also need to engage in reading for their own enjoyment. However, Grabe and Stoller (2013) state that the extent to which learners engage in reading (positively or negatively) both at home and at school is influenced greatly by their attitude towards reading and also their ability to read.

As stated in the PIRLS 2011 Assessment Framework, learners' attitudes towards reading are a central factor affecting reading performance. A learner's reading attitude plays a key role in whether or not he or she becomes a competent reader (Mullis et al. 2011). According to McKenna et al. (1995) and Sainsbury and Schagen (2004), learners who have a negative attitude towards reading are less likely to read voluntarily and will overall read less than their readingpositive companions and generally achieve lower levels of learning when compared with their peers. Over time, the ability gap between learners becomes larger (Guthrie \& Wigfield 2000). Likewise, Mckenna and Kear (1990) state that a poor reading attitude may contribute to aliteracy, a situation when fluent readers choose not to read when other options like television and video games exist, as noted in the studies conducted by the National Endowment for the Arts (NEA) (2007) and Mokhtari, Reichard and Gardner (2009).

The big challenge for teachers and other stakeholders interested in education and literacy development is not only about getting learners to read but also about getting them to enjoy reading (Clark \& Rumbold 2006). At the FP Level, learners trudge through set readers in class in the presence and assistance of a teacher (Hoadley 2016), but there is no guarantee that they will open another book when they get back home or during their spare time. Therefore, good readers are those who have a positive attitude towards reading, and who read for pleasure. If children do not enjoy reading when they are young, they are unlikely to do so when they are older (Clark \& Rumbold 2006).

Learners' attitudes towards reading have been found to have an effect on both engagement and achievement in reading (Mullis et al. 2011). Given the relationship between reading achievement and attitude, Guthrie and Wigfield (2000) state that it is important to promote learners' level of engagement early in their education. It is vital that learners learn to read efficiently at an early age as difficulties may impede upon self-concept and self-esteem in later years when peer relations and pressures become more evident (Myoungsoon \& Heekyoung 2002).

Gillespie (1993) states that: 'For students to be successful readers they must have a positive affective predisposition toward reading instruction' (p. 336). Once a positive attitude is developed, reading achievement and reading time increase (Alexander \& Filler 1976). Given the importance of positive attitudes towards reading, it is crucial that learners be given every opportunity to become involved in reading and practise so that they will eventually become successful readers. Strickland and Morrow (1990) state that continued exposure to books helps in the development of children's vocabulary and gives them a sense of story structure, which assists in the process of learning to read. Interestingly, Day and Bamford (1998) state that the most important point about attitudes is that they are subject to change as they are not concrete. In the current study, the researcher sought to establish the attitudes of learners towards reading by using drawings before implementing a responsive reading programme with the aim of positively influencing learners' reading attitudes and nurturing positive reading habits.

\section{Drawings: A methodological tool to reveal learners' attitudes towards reading}

A number of researchers (Ajzen 2005; Baker 1992; Eagly \& Chaiken 2007; Moodley 2003) have considered measuring attitude as a difficult task, as it is not directly observable and is also very subjective. Moodley (2003) postulates that attitude cannot be measured directly or accurately because people's thoughts and feelings are hidden components that cannot be measured directly. Likewise, Ajzen (2005), who presents attitudes and personality traits as similar concepts, emphasises that both attitudes and traits cannot be observed because they are not part of a person's thoughts and feelings. Eagly and Chaiken (2007) also stress the challenge of measuring attitude by stating that 'an attitude is inside the person, not directly observable and is manifested by covert or overt responses' (p. 584). A general overview of the development of attitudes throughout school years and in many studies conducted has been documented through surveys and meta-analysis. For example, in previous studies (Walberg \& Tsai 1995; Yamashita 2013), attitudes towards reading have been assessed by learners' written responses to written statements about reading. Baker (1992) posits that 'this measurement of an individual's attitude is unlikely to reveal their attitude perfectly' (p. 18). 
This discussion reveals the challenge of investigating attitudes. To provide a solution to the challenges in measuring attitudes, the present study explored the use of children's drawings to determine their attitudes towards reading. Christensen and James (2008) state that drawings are a relaxing and enjoyable activity that children choose both in and out of the classroom as a medium through which to communicate their experiences, feelings and beliefs. In addition, drawing enhances communication which makes it an appropriate approach in exploring the reading experiences of young learners without being restricted by either their home language (HL) or their second (additional) language (L2) to fully express themselves.

A limited number of educational studies have used visual images such as drawings to investigate a variety of issues in the classroom context. For example, in South Africa, Murris and Thompson (2016) used drawings as a way of investigating how young children responded to a particular picture book. Similar to the current study, Kendrick and McKay (2004) used young children's drawings (aged 5-6 years) as a method of investigating their perception and understanding of literacy across the broad context of their lives.

Malchiodi (1998) claimed that unlike questionnaires with predetermined statements, drawings provide a multidimensional view of children, as drawing tasks are open-ended, unstructured and not constrained by language. Drawings are also childcentred, fun, imaginative, expressive and engaging for most young children in the Foundation Phase (FP).

\section{Theory informing the study}

The use of drawings in this study acknowledges that all modes of meaning-making are equally significant; thus, the study recognises that there are multiple literacies. As a result, the study adopts a broad definition of literacy that goes beyond being just able to read and write or decode but incorporates the child's ability to communicate using a variety of means of representation, including drawings.

The study adopts Vygotsky's (1978) sociocultural theory as a theoretical framework. Specifically, it recognises the following:

- Drawings are a way of knowing, a particular kind of speech and mediating tool within and across cultures in children's learning.

- Young children are situated as learners by the societies in which they are nurtured and educated.

- The child is a co-constructor of meaning and an active player in his or her own world.

- The relationship between the child and the environment enables us to understand the social and cultural setting into which the child is born.

- The role of the 'more knowledgeable other' (MKO) and collaboration is significant in children learning to read.

In addition, the study integrated a range of semiotic theorists in analysing the learners' drawings. Furth (2002) considers that there are three interpretive principles involved in the descriptive analysis of pictures. The first principle is to note the child's initial impression of a picture that describes his or her feeling. The second principle is to systematically comb through the picture objectively for several elements or characteristics such as words in the drawing and figures presented in the drawing, and the surrounding world. Haring and Sorin (2014) refer to this step as content analysis. The third principle involves a synthesis of the observations gathered into a report. The fourth principle involves affording learners an opportunity to talk about their drawings so as to validate their own initial interpretation of the drawings, as suggested by Malchiodi (1998).

\section{Methodology}

This is a qualitative, interpretative study which made use of learners' drawings for a situational analysis phase. According to Cohen et al. (2007), an interpretative study is characterised by a concern for individual experiences, and the aim of the research is to learn from a phenomenon, while also attempting to initiate change. It ultimately seeks to be transformative. In the current study, drawings were used to explore learners' attitudes towards reading before the implementation of a reading intervention (Phase 2 ).

The prompt for the drawings was 'Draw a picture of reading and write about your drawing (caption the drawing). It can be a drawing of your feelings about reading or your experiences with reading'. This was followed by follow-up focus group discussions with a subset of the sample to explain and discuss in detail their drawing. Based on my experience as a researcher, the majority of Grade 3 learners in township schools struggle to communicate in English, and a number of them also struggled with reading in their HL; therefore, the discussions were conducted in isiXhosa.

In addressing the ethical issues of the study, a condition was laid out that only those learners with signed consent forms from their guardians would be allowed to be part of the study and that participation was voluntary. All Grade 3 learners in the selected school were invited to participate in the study. All the 37 learners that were given consent forms brought them back all signed. The participants were made aware of their right to anonymity and to withdraw from the study at any point in time. In the data presentation, 10 selected learners' drawings were used. These were presented with pseudonyms to protect their identity.

\section{Research question}

The main research question of the study was: What is the nature of learners' reading attitudes in Grade 3? In addition, the aim of the study was to use drawings as a methodological tool to investigate learners' attitudes towards reading.

\section{Research site and participants}

This article presents part of a larger study that was conducted with two Grade 3 classes from two primary schools that were accessible, convenient and located in close proximity to 
Grahamstown. The research Site A, reported in this article, is a township school in Grahamstown, which is historically disadvantaged and a no-fee paying public school. The state bears all the costs with no contribution from the learners' parents. At this particular school, from Grade R to Grade 3, isiXhosa, which is the learners' HL, is used as a medium of instruction, and learners in Grade 4 switch to using English, which is a language of teaching and learning, and for most learners in this context, it is their second language.

The article presents findings from 10 learners' drawings ( 5 boys and 5 girls) out of a sample of 37 Grade 3 learners (17 girls and 20 boys) aged between 9 and 11 years. A number of the learners struggle with reading and writing in the English language and are from underprivileged and impoverished backgrounds. Therefore, the use of drawings was appropriate, as it did not require high literacy skills. It was considered inclusive as all children, including those who otherwise might not have expressed their ideas, were allowed a rare insight into their lives and thoughts. The presented learners' drawings were selected on the basis of having clearly captured learners' attitudes and experiences about their reading, which was the focus of the study. The drawings are also a good representation of the rest of the drawings that were collected from both research sites. The method of using children's drawings to understand their reading attitude as applied adds to the uniqueness of this study.

\section{Procedure}

The drawings were administered to all the participating learners on the same afternoon in the learners' classroom. The prompt question was read out to the participants in both languages, which is isiXhosa their HL and English, which is an additional language. Learners were given enough time to process the question, draw, caption and even colour their drawings using the crayons that were provided. Following the drawing process, the researcher met with the learners in focus groups to explain their drawings. The focus group discussions were organised in such a manner that each group consisted of four members. The length of the focus group discussion varied between $30 \mathrm{~min}$ and $1 \mathrm{~h}$. In instances where the discussions took a shorter duration, it was because the group lacked involvement and some learners' responses were very short, in most cases one word answers. With their drawings in front of them, learners were free to explain and discuss their drawings in a language they were comfortable in. Talking about their drawings allowed the participants to voice their perspectives about their drawings and to improve their communication skills. Malchiodi (1998) states that it is important that learners be given an opportunity to explain their drawings in order for the researchers to understand the learners' interpretations of the drawings. Their explanations also helped to validate my initial interpretation of the drawings, for example, where and when the reading activity took place.

\section{Data analysis}

The unit of analysis was the literacy event portrayed in the drawing. In the process of analysing these drawings, a range of semiotic theories were integrated. The first step in the process of analysis was writing down the first impression, that is, viewing the drawing as 'mysterious' (Malchiodi 1998:19). Informed by Kress and Van Leeuwen (1996), the next step was to get an idea about what is in the drawing (looking for what natural or human objects are present in the drawing). After this step, a discussion with the learners in focus groups of four learners was held. Each learner was given an opportunity to talk about their drawing and the accompanying text in each drawing. The final step was the synthesising of the findings and looking for emerging themes in the drawings.

The following section presents and discusses the findings of the study, with examples of different drawings about reading portrayed by the selected participants.

\section{Discussion and analysis of the findings}

The analysis of the learners' drawings resulted in five categories of reader experiences as will be discussed in detail in the following sub-sections. The first category consisted of learners who perceived reading as an activity which happens in a formal setting with the assistance of a teacher. In the second category, the learners viewed reading as a social activity while in the third category learners viewed reading as an isolated activity. In the fourth category, the learners were aware of the positives associated with reading which in turn motivated them to read more. Finally, there were learners who indicated that the setting or reading environment hindered them from enjoying reading. Hence, they had mixed attitudes towards reading (i.e. love-hate relationship with reading).

\section{Reading in formal settings and domains}

The context, in other words, the environment in which reading is presented, has the potential to influence the learner to either engage in or avoid the reading task as represented in Figure 1 and later on in Figure 5. Further elements of the reading environment that are crucial are a pleasant and informal atmosphere, where one has a choice of what to read, that is, the genre and the language to read in. One of the most striking aspects in which learners represented their reading was that reading mostly happened at school, in confined spaces. As shown in Figure 1, some learners' drawings presented reading as an activity taking place at school in the presence of the teacher. This is understandable because the majority of South African learners from disadvantaged backgrounds and print-poor communities have limited access to reading material (Fleisch 2008). There is also lack of reading material especially in African languages and many learners stay with parents who have little time or ability to read with their children. During the focus group discussions about their drawings, learners stated that they portrayed reading as an activity happening at school because of lack of reading material at home. 


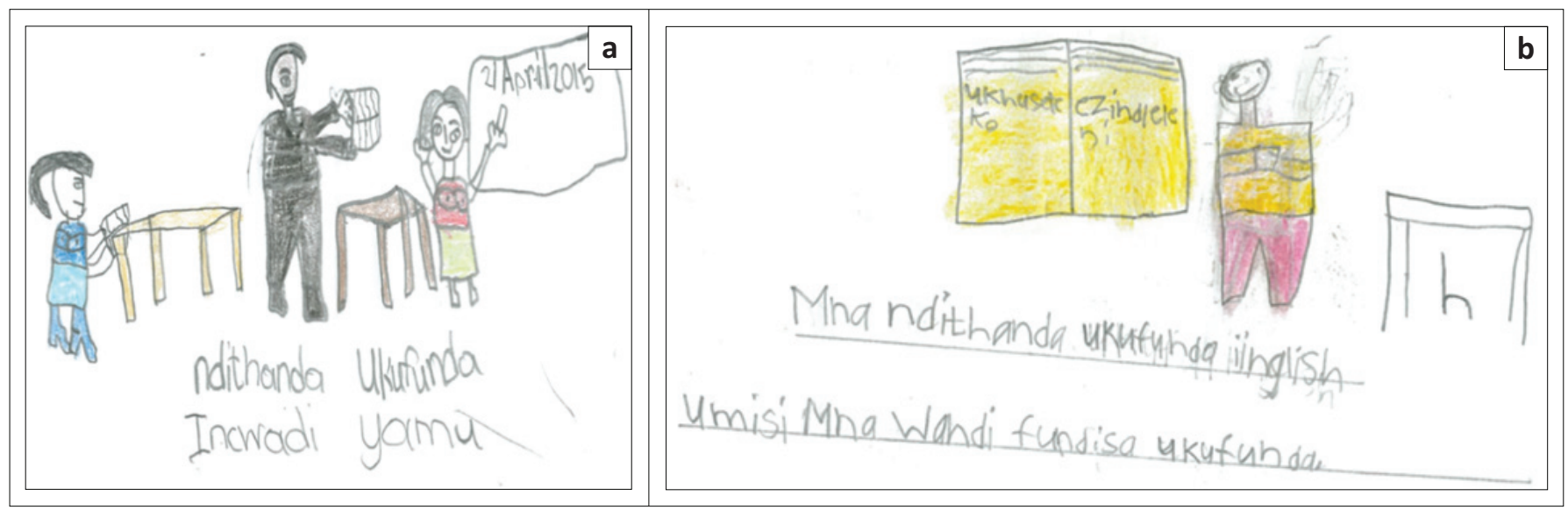

FIGURE 1: Reading in formal settings and domains: (a) I like to read my book and (b) I like to read in English. My teachers taught me how to read.

For example, based on my initial interpretation of the drawing (Step 1 of the analysis), Phila's unique drawing of reading (Figure 1a) portrays himself standing behind his desk, holding a book and asking for his teacher's guidance. He clearly positions himself as a reader. In front of the desk is his teacher pointing at the chalkboard. An assumption can be made that this particular learner's perception about reading is:

'it happens at school, in the presence of a teacher to help or guide one's reading'. [Phila, male]

The teacher is assumed by the learner to be the MKO (Vygotsky 1978) and has to be present to initiate and facilitate reading activities. Within the confines of a classroom, reading is a scheduled activity with the teacher. As such, reading is perceived as a subject that one has to be guided or instructed to do without taking the initiative.

In our focus group discussion (Step 4 of the analysis), the learner confirmed the researcher's initial interpretation of the drawing:

'This is me in my black trousers and school blazer, I go to the teacher each time I don't understand anything or when I need help with difficult words'. [Phila, male]

The other three members of this particular focus group were in agreement with the fact that in their classroom they considered their teacher as a role model who supports their reading activities. According to Rimensberger (2014), the way learners perceive their teacher will affect their attitude towards reading. Having supportive teachers promotes learners' feelings of control and confidence in their ability to succeed. In addition, learners indicated that at school they depended on their teachers to read for the learners. This is understandable because these learners are not yet proficient readers. In addition, the limited access to reading resources makes it difficult for each learner to have opportunities to read independently. The teacher therefore often reads aloud for them. However, in an interview conducted by Koen from City Press (2015), Bloch highlighted that lack of access to reading material and reading opportunities can negatively impact on learners' reading attitude as learners need to continually read in order to appreciate and love reading.

\section{Reading as a social activity}

Traditionally, reading has been viewed as a purely individualistic skill. However, two learners in this article presented reading from a completely different perspective. They presented reading as a social activity. The sociocultural theory of learning regards reading as a social skill and emphasises active participation and interaction of the learners involved.

In a social learning context, learners have the power to choose what to read, when to read and how to read. They view reading as a pleasurable, fun activity rather than a chore. This is indicated in the drawings (Figure 2) with upturned mouths and smiles, which are perceived as cultural conventions symbolising happiness and joy (Kress \& Van Leeuwen 1996). Also evident in the drawings (Figure 2) is the presentation of reading as an activity that one does in the company of someone else. Shared or paired reading was evident in these learners' drawings. Learners explicitly captioned their drawings as reading with their siblings or friends. For these learners, home, family and school were the focal points of reading. When reading is presented to the learners as an activity that the reader is entirely in control of, learners tend to like and enjoy reading, which results in positive attitudes towards reading.

These drawings reflect learners' knowledge and acceptance that reading is a social activity and that it can maintain friendship or family relationships. For example, in the focus group discussion, one mentioned (Figure 2a):

'I always find time to read with my sister, she is doing Grade 8 and can read well in English'. [Mandla, male]

Thandi's caption of her drawing (Figure 2b) clearly shows the social nature of reading with her friend as they laugh, joke and ask each other about their reading. Drawings about learners' reading with friends or siblings may suggest that there is lack of parental involvement when it comes to reading activities happening at home. Siblings and friends are the ones who seem to read for these learners more than their parents. In this particular context, it seems the parents are illiterate or absent in the learners' lives. 


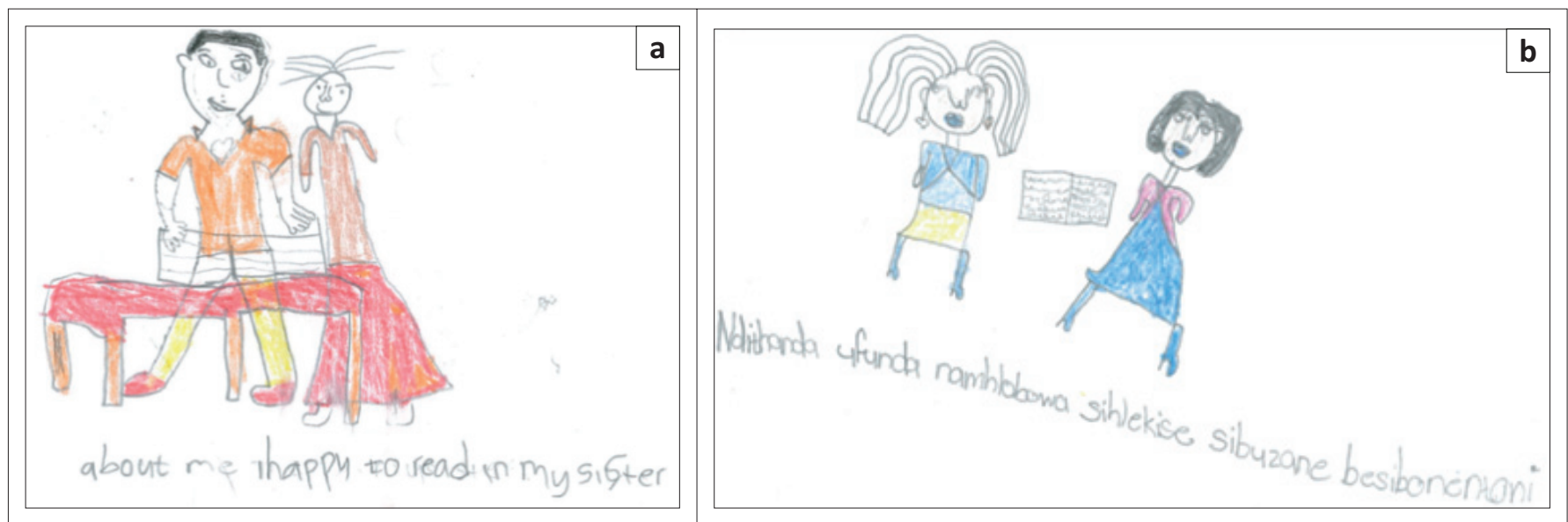

Note: (a) 'About me, I am happy to read in (with) my sister'. Mandla's drawing above shows two figures; The one holding an English book is him because he loves English and reading in that language. Hence, he also captioned his drawing in English. The other one is his sister; (b) Thandi's picture is set in the home context. In the picture there are two figures - herself and a friend. The caption of the drawing is in isiXhosa, and it reads 'I am reading a book with my friend, we laugh/joke and ask each other about what we have been reading about'. The caption and the picture show active engagement in the reading process.

FIGURE 2: Reading as a social practice: (a) Mandla's picture (b) Thandi's picture.

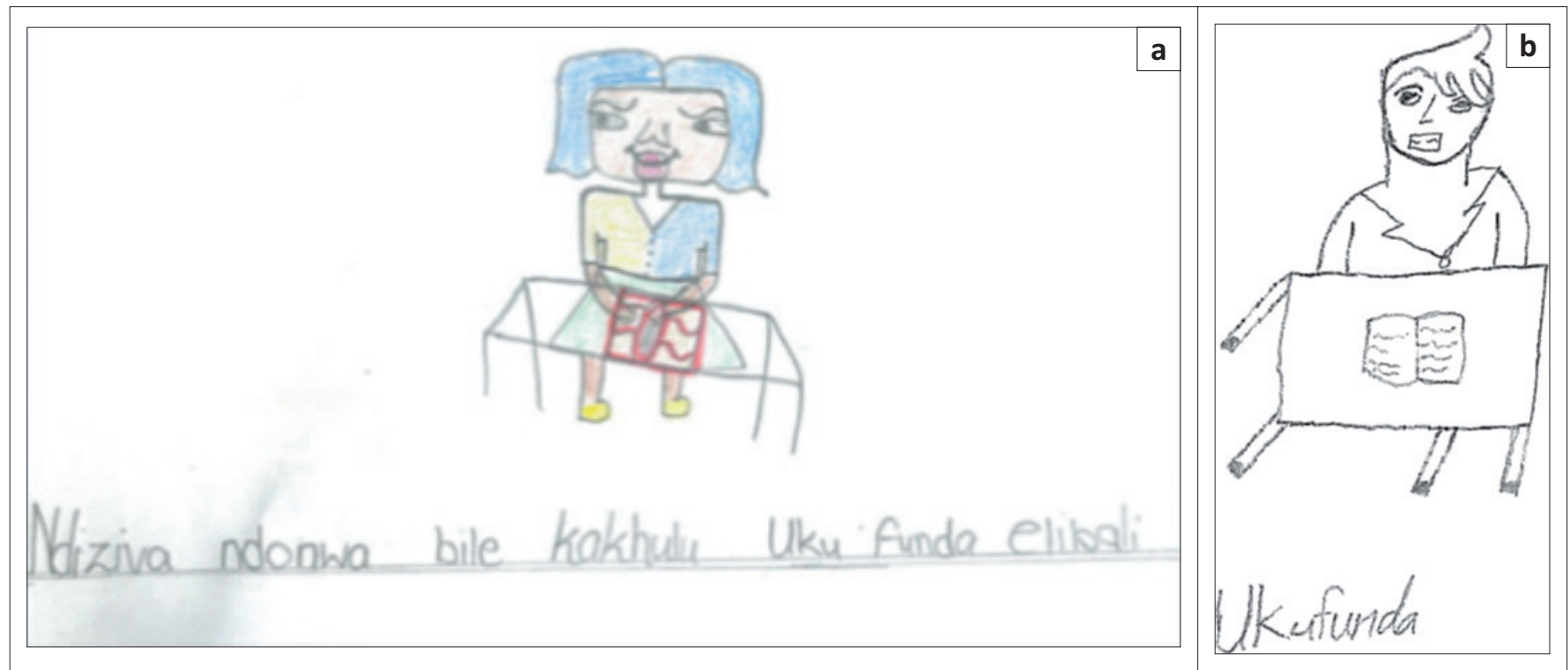

FIGURE 3: Reading as an isolated activity: (a) I feel very happy reading this book and (b) reading.

\section{Reading as an isolated activity}

Generally, reading has been seen as a necessity for one to succeed at school and to be able to get a job and not as an enjoyable activity (Rimensberger 2014). Hence, traditionally, it has been perceived as an isolated activity. It is expected that during reading, one sits quietly alone and gets lost in the world of reading. However, the social interaction during and after reading instils the joy of reading. In most FP classrooms, the idea of reading alone might be daunting for some learners, while for others it is the only time they get to read at their own pace and discover the joys of independent reading. However, this immediately formalises the activity and presents reading as an activity that occurs separate from one's everyday routine - meaning that a special time and a place has to be set aside for reading; yet, reading can happen anywhere at any given time.

While some learners presented reading as a social activity (Figure 2), others did not portray family members, friends or siblings as part of their reading activity. Through their drawings, learners presented reading as an activity that they did on their own. As shown in Figure 3, learners drew pictures of themselves seated and reading alone. They mentioned that they preferred to sit in a quiet place and read, so as to concentrate and understand what they are reading. During focus group discussions, the following was stated (Figure 3a):

'I like to sit alone and read quietly without any disturbance' [Thandi, female]

Another (Figure 3b), said:

'You see ma'am, some children read out aloud, at the end you focus on them and not your reading. I prefer reading alone in a quiet place'. [Siya, male]

Considering the background in the drawings and the facial expressions of the people in the drawings, one can infer that it is a quiet, formal environment, and learners are content with what they are doing. 


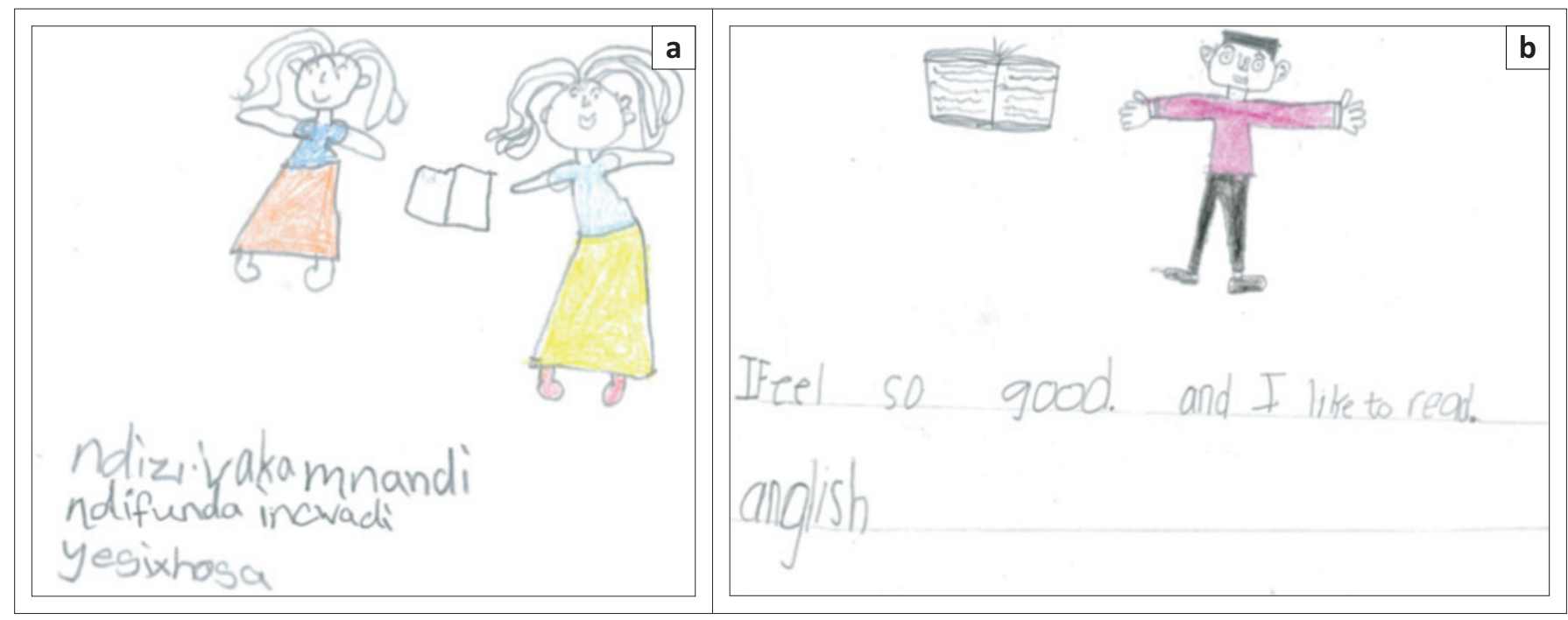

FIGURE 4: Imagined identies as readers: (a) I feel content when I read an isiXhosa book and (b) I feel so good and I like to read English.

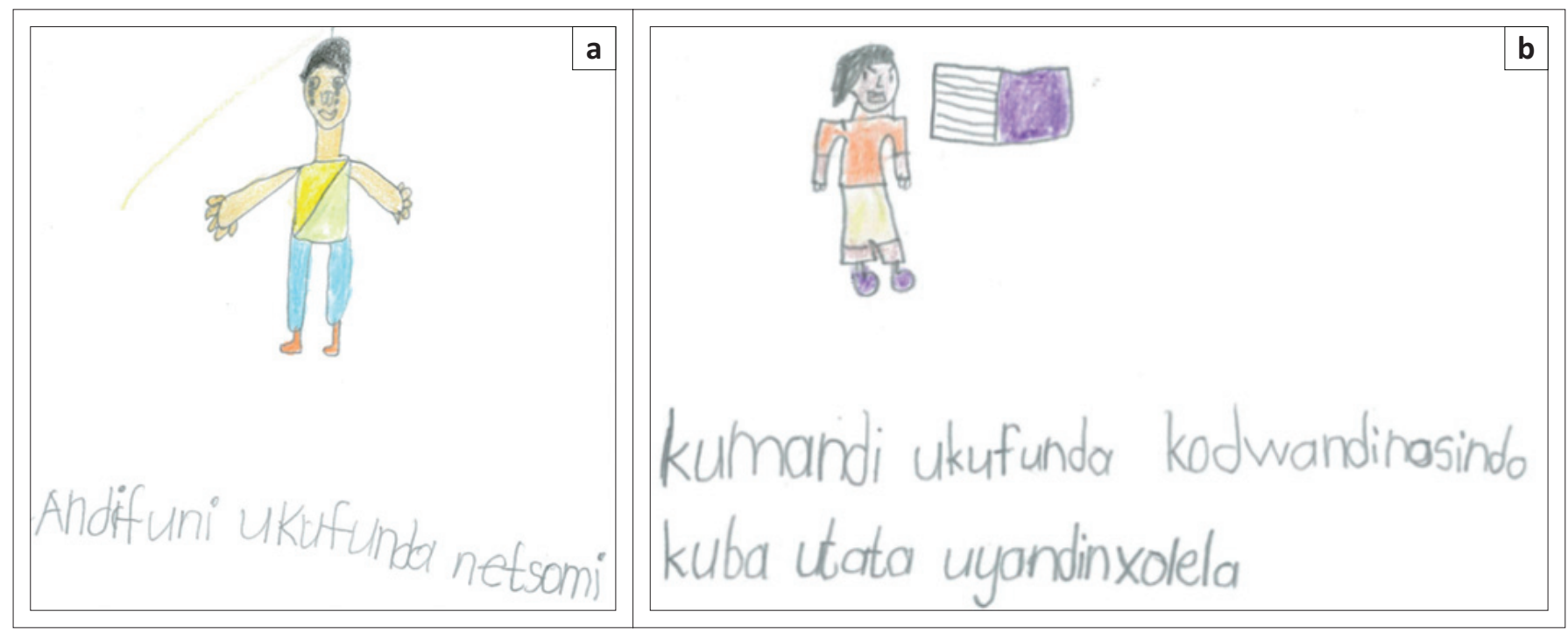

FIGURE 5: Love-hate relationship towards reading: (a) I do not want to read folktales and (b) reading is enjoyable, but I am angry because my father shouts at me.

\section{Reading as a purposeful activity}

In the selected sample of learners, two learners highlighted the purpose of engaging in reading. Having an awareness about the positive gains of reading and the purpose of reading (i.e. excitement, contentment and improving one's reading skills) might be a motivation for learners to read. Learners have to feel the need for reading before they engage in the activity and enjoy what they are doing. In Figure 4a, Noma mentioned that she feels content when she is reading a book in isiXhosa, while Jabu's caption in Figure 4 b states that he feels good when he is reading in English.

In the follow-up discussion, the two learners mentioned how they loved reading in their preferred languages, including isiXhosa, the mother tongue of the learners in the studied group. They also highlighted the need to learn to read proficiently in English as they were aware of the status of the language and the importance of being bilingual. The explanations of these drawings provide insight into how these learners see themselves as readers in the current context as emergent bilinguals.

\section{Reading as an activity that one can love or hate}

Drawings of four learners provided an insight into the learners' reading experiences and how the love or hate relationship they have towards reading is manifested. In Figure 5, the concept of reading is understood and represented as an activity that one can love or hate, depending on the situation and circumstances. For example, in the drawing in Figure 5a, Luvo explained that he loved reading but did not like reading a particular genre (folktales). He added that each time he was asked to read such stories, he felt like crying and other learners laughed at him; hence, the tears running down his face.

In Figure 5b, Sisa mentioned that she liked reading but the negative attitude towards reading was noted as being influenced by what happens during reading. In the drawing and interpretation, the learner mentioned that her father shouts at her when she is reading:

'I love reading, but my father shouts at me when I make mistakes'. 
From my experience and observation, typically this is what untrained and impatient parents do in our society. Reading time for many children is not a pleasurable activity as there is no room for mistakes. Such actions instil fear and affect learners' confidence and motivation in reading. For learners to read and be lifelong readers, reading has to be presented as an activity that is enjoyable, fun (social activity) and not accompanied with pain and frustration (Whittingham \& Huffman 2009). It became evident that the two learners needed some form of intervention; as a result, a decision was made that during the implementation phase, rules will be made so that learners will not laugh at each other. Although it was beyond the scope of this research, the research assistant, familiar with the community, shared Sisa's feelings with her parents and made them aware of the importance of presenting reading as a pleasurable activity to their little girl.

Through different individual experiences with reading, learners have conceptualised and presented reading in varying ways as discussed, thus responding to the following research question: What is the nature of learners' reading attitudes in Grade 3? Data collected from the learners' drawings therefore confirm Kendrick and Mckay's (2009) claim that 'drawings give insight into spontaneous concept development, that is, into the meaning of concepts that have developed from the children's own experiences' (p. 55). When I initially shared these findings with the two Grade 3 teachers and later with the school principal, they were all overwhelmingly surprised at the ability of their learners to express such complex understandings of reading. They were also not aware of some of their learners' history and experiences about reading, which led to the individual learner either approaching or avoiding the reading activity.

\section{Implications of the findings}

The findings from the data allowed me to reflect on areas that needed attention so as to be able to develop an appropriate reading programme that would cater for all the learners by addressing the tensions and contradictions that surfaced as hindering effective reading. Some important insights that emerged during this phase are listed below:

- Implement a bilingual programme, as this was expressed by the learners. In explaining their drawings, they had varying language preferences (I like to read in isiXhosa or I like to read in English).

- Scaffold reading in both English and isiXhosa, as these were emergent bilingual learners. Also, some learners expressed the need to learn to read in both languages during our focus group discussions.

- Expose learners, as part of scaffolding reading, to different exciting reading activities before, during and after reading so as to nurture positive reading attitudes.

- Give learners opportunities to choose what they want to read, when to read and how to read so as to allow them to enjoy reading and take charge of their development.

- Provide a variety of reading material across different languages (isiXhosa and English) so as to cater to every learner's needs. It was shown that not all learners like reading folktales, a popular genre in the FP (see Figure 5a).
- Establish a reading environment guided by a sociocultural perspective which presented reading as a fun activity not a chore, and allowed for collaborative learning and interaction. In this setting, there was room for mistakes and learners were not scolded or laughed at but instead were motivated to read.

Teach various reading strategies. The Extensive Reading Programme afforded learners an opportunity to be read to, to read on their own and to read with or for each other. As shown in the drawings, some learners preferred reading with their peers, some preferred to read individually while others saw their teachers as role models when they read aloud. These insights informed the implementation of the actual ERP which was carried out in Phase 2 of the research.

\section{Conclusion}

This study shows the importance of first conducting a situational analysis in a literacy intervention. The first phase of situational analysis reported on in this article provides crucial information about learners' attitudes, reading experiences and their perspectives about reading so as to be able to implement a reading programme that will cater to the needs of all the learners. The study also challenges other researchers to see the importance of using drawings to obtain a better understanding of learners' literacy experience.

In addition, the use of drawings with young learners afforded learners an opportunity to express themselves; even the weakest learners in the classroom expressed themselves without any verbal language limitations. Therefore, the inclusion of a drawing activity in this study opened possibilities for inclusion and active participation of the majority of the participants. Vygotsky (1978) states that drawings are the earliest representations of experience of children and that they stimulate their narrative impulse to create stories. Finally, participants of this study produced unique drawings of their reading into which their personal and social histories were woven. As a researcher, the drawings gave me a glimpse into the experiences that learners have had with reading both at home and at school which might have positively or negatively influenced their attitudes towards reading. Therefore, this collection of drawings indicate that through learners' drawing of their reading experience, researchers and teachers can come up with additional ways of investigating and understanding learners' constructions of reading. Had this study relied solely on learners' responses to a questionnaire or interviews about their reading, it could have resulted in limited insights about learners' attitudes towards reading and their reading perspectives and experiences.

\section{Acknowledgements}

The author would like to thank the Grade 3 learners from the two research sites for their participation in this study and their permission to use data collected throughout the research process. 


\section{Competing interests}

The author declares that there are no financial or personal relationships that may have inappropriately influenced the writing of this article.

\section{References}

Ajzen, I., 2005, Attitudes, personality, and behaviour, 2nd edn., Open University Press, Milton-Keynes, England.

Alexander, J. \& Filler, R.C., 1976, Attitudes and reading, International Reading Association: Reading Series, International Reading Association, Newark, DE.

Baker, C., 1992, Attitudes and language, Volume 83 of Multilingual Matters, Multilingual Matters, Clevedon.

Christensen, P. \& James, A., 2008, 'Introduction: Researching children and childhood cultures of communication', in P. Christensen \& A. James (eds.), Research with children: Perspectives and practices, pp. 1-9, Routledge Flamer, London.

Clark, C. \& Rumbold, K., 2006, Reading for pleasure a research overview, The National Literacy Trust, London.

Cohen, L., Manion, L., Morrison, K. \& Morrison, K.R.B., 2007, Research methods in education, Routledge, New York.

Cosgrove, M.S., 2003, 'Students' views on the purposes of reading from three perspectives students, teachers, and parents', New England: Reading Association perspectives students
Journal $39,28-36$.

Day, R. \& Bamford, J., 1998, Extensive reading in the second language classroom, Cambridge University Press, New York.

Eagly, A.H. \& Chaiken, S., 2007, 'The advantages of an inclusive definition of attitude', Social Cognition 25(5), 582-602. https://doi.org/10.1521/soco.2007.25.5.582

Fleisch, B., 2008, Primary education in crisis: Why South African school children underachieve in reading and mathematics, Juta, Johannesburg.

Freire, P., 1984, The politics of education: Culture, power, and liberation, Bergin \& Garvey Publishers, South Hadley, MA.

Furth, G., 2002, The secret world of drawings: A Jungian approach to healing through art, Inner City Books, Toronto.

Gillespie, C., 1993, 'College students' reflections on reading', Reading Horizons 33, 329-340.

Grabe, W. \& Stoller, F.L., 2013, Teaching and researching reading, 2nd edn., Taylor and Francis, New York.

Guthrie, J.T. \& Wigfield, A., 2000, 'Engagement and motivation in reading', in M.L. Kamil, P.B. Mosenthal, P.D. Pearson \& R. Barr (eds.), Reading research handbook, vol. 3, pp. 403-424, Erlbaum, Mahwah, NJ.

Haring, U. \& Sorin, R., 2014, 'The CID lens: Looking at children's drawings using content, interpretive, and developmental methods', International Journal of Arts
Education 8, 15-29. https://doi.org/10.18848/2326-9944/CGP/v08i03/36125

Hoadley, U., 2016, A review of the research literature on teaching and learning in the foundation phase in South Africa, Stellenbosch University, Stellenbosch, South Africa

Kendrick, M. \& McKay, R., 2004, 'Drawings as an alternative way of understanding young children's constructions of literacy', Journal of Early Childhood Literacy 4(1), 109-128. https://doi.org/10.1177/1468798404041458

Kendrick, M. \& McKay, R., 2009, 'Researching literacy with young children's drawings', in M. Narey (ed.), Making meaning, pp. 51-687, Springer, New York.
Koen, G., 2015, 'Are we teaching reading wrong?', City Press, 26 July, viewed 12 July 2017, from http://city-press.news24.com/Trending/Are-we-teaching-readingwrong20150726

Kress, G. \& Van Leeuwen, T., 1996, Reading images - The grammar of visual design, Routledge, London.

Malchiodi, C.A., 1998, Understanding children's drawings, The Guilford Press, New York.

McKenna, M.C., Ellsworth, R.A. \& Kear, D.J., 1995, 'Children's attitudes toward reading A national survey', Reading Research Quarterly 30, 934-956. https://doi.org/ $10.2307 / 748205$

McKenna, M.C. \& Kear, D.J., 1990, 'Measuring attitude toward reading: A new tool for teachers', The Reading Teacher 43(8), 626-639. https://doi.org/10.1598/ RT.43.8.3

Mokhtari, K., Reichard, C.A. \& Gardner, A., 2009, 'The impact of internet and television use on the reading habits and practices of college students', Journal of Adolescent and Adult Literacy 52(7), 609-619. https://doi.org/10.1598/JAAL.52.7.6

Moodley, V., 2003, 'Language attitudes and code-switching behaviours of facilitators and learners in LLC senior phase OBE classrooms', PhD thesis, University of Natal, Durban.

Mullis, I.V.S., Martin, M.O., Kennedy, A.M., Trong, K.L. \& Sainsbury, M., 2011, PIRLS 2011 assessment framework, TIMSS \& PIRLS International Study Center Lynch School of Education, Boston College, Chestnut Hill, MA.

Murris, K.S. \& Thompson, R., 2016, 'Drawings as imaginative expressions of philosophical ideas in a Grade 2 South African literacy classroom', Reading \& Writing 7(2), a127. https://doi.org/10.4102/rw.v7i2.127

Myoungsoon, K. \& Heekyoung, K., 2002, 'The differences in attitudes toward emergent literacy of children among teachers, mothers, and fathers in kindergartens and day care centers in Korea', Reading Improvement 39(3), 124-148.

National Education Evaluation and Development Unit Report, 2013, The state of literacy teaching and learning in the foundation phase, 2013. NEEDU, Pretoria.

National Endowment for the Arts (NEA), 2007, To read or not to read: A question of national consequence, National Endowment for the Arts, Washington, DC.

Progress in International Reading/Literacy Study, 2006, viewed 19 July 2017, from www.pirls.org

Progress in International Reading/Literacy Study, 2011, viewed 19 July 2017, from www.pirls.org

Rimensberger, N., 2014, 'Reading is very important, but...: Taking stock of South African student teachers' reading habits', Reading \& Writing 5(1), Art. \#50, 1-9. https://doi.org/10.4102/rw.v5i1.50

Sainsbury, M. \& Schagen, I., 2004, 'Attitudes towards reading at ages nine and eleven', Journal of Research in Reading 27(4), 373-386. https://doi.org/10.1111/j.14679817.2004.00240.x

Spaull, N., 2013, South Africa's education crisis, Centre for Development and Enterprise (CDE), Johannesburg.

Strickland, D.S. \& Morrow, L.M., 1990, 'Family literacy: Sharing good books', The Reading Teacher 43(7), 518-519.

Vygotsky, L.S., 1978, Interaction between learning and development. From: Mind and society, Harvard University Press, Cambridge, MA.

Walberg, H.J. \& Tsai, S.L., 1995, 'Correlates of reading achievement and attitude: A national assessment study', Journal of Educational Research 78(5), 159-167.

Whittingham, J.L. \& Huffman, S., 2009, The effects of book clubs on the reading attitudes of middle school students, Reading Improvement 46(3), 130-136.

Yamashita, J., 2013, 'Effects of extensive reading on reading attitudes in a foreign language', Reading in a Foreign Language 25(2), 248-263. 